\title{
ANÁLISE DA GESTÃO DO PROCESSO DE PERSONALIZAÇÃO DE IMÓVEIS RESIDENCIAIS
}

PROCESS MANAGEMENT ANALYSIS CUSTOMIZATION OF RESIDENTIAL PROPERTIES

\author{
Marco Aurellio Polenghi Pagliaroni', Sheyla Mara Baptista Serra'
}

RESUMO: A personalização vem sendo utilizada no setor de construção habitacional para adaptar o imóvel residencial às necessidades dos clientes, aumentando o valor do produto Um dos motivos que levaram à implantação da personalização no cenário mundial foi o aumento do padrão socioeconômico de parte da população, que passou a ser capaz de satisfazer anseios relativamente individualizados, sendo estimulada também pela tendência de personalizar em outros setores econômicos. Entretanto, devido à falta de planejamento e de um eficaz sistema de comunicação e gestão de informações voltadas à adoção da personalização, observam-se atrasos e retrabalhos na finalização das etapas construtivas. Este trabalho teve como objetivo verificar o fluxo de informações em construtoras que realizam obras de edificações residenciais e oferecem a personalização aos clientes. Como método de pesquisa foram realizados quatro estudos de caso com a aplicação de questionários, observação direta e entrevistas. Assim, foi possível verificar a organização dos processos internos envolvidos na personalização de imóveis residenciais, esquematizando os fluxogramas de cada empresa, que mostram a comunicação entre os envolvidos, desde a venda do imóvel para o cliente até a entrega dos materiais necessários para a execução da obra e das personalizações. Como resultado adicional é proposto um fluxograma modelo para melhorar a gestão da personalização de imóveis.

PALAVRAS-CHAVES: Customização de Imóveis; Planejamento e Controle da Construção; Gestão de Materiais; Setor de Suprimentos.

ABSTRACT: Customization has been used to adapt building to customer needs, thus improving the value of the product. One of the reasons of the implementation of personalization worldwide was the increase of the population socioeconomic standards, people are now able to reach individual needs, and follow the tendency to customize, present in other sectors of economy. However due to lack of planning and an effective system of communication and information management aimed to adoption of customization, there are delays and rework on the completion of construction activities. This study aims to determine information flow of residential building companies that offer customization to customers. As research methodology, four case studies were observed, with questionnaires, direct observations and interviews. Similarly, it was possible to understand how the internal processes of these companies are organized, creating flow charts of each company, that show the communication between the involved, from the sale of the housing to the client until the delivery of materials required for the execution of customization activities. As additional result, it is proposed a template flow chart aimed to increase the management of customization.

KEYWORDS: Customization Process; Planning and Control of Construction; Materials Management; Supply Sector. 


\section{INTRODUÇÃO}

O mercado imobiliário da indústria da construção civil passa por momentos de crescimento. Tendo em vista a progressiva competitividade do mercado, empresas construtoras vêm adotando medidas para se manter rentáveis, que envolvem não somente a melhoria do processo de produção, como também o atendimento às necessidades dos clientes (CARVALHO; JUNGLES, 2004). Brandão e Heineck (1996), há duas décadas, afirmavam que o mercado imobiliário se tornava mais competitivo a cada dia. Os mesmos autores completaram que de um lado as construtoras e incorporadoras começaram a ampliar qualitativa e quantitativamente os atributos dos imóveis ofertados, buscando diferenciais mercadológicos, e do outro lado os clientes, bem informados, exigiam cada vez mais.

Ao mesmo tempo, parte da população passou a ter aumento do padrão socioeconômico, criando condições que levaram à tendência de customizar presente em vários setores da economia, como na indústria automobilística e de eletrodomésticos, como relata Campanholo (1999). Assim, foi possível implantar a personalização da construção no cenário mundial, que passou a ser capaz de satisfazer anseios relativamente individualizados dos clientes em potencial.

A personalização passou a ser utilizada pelo proprietário ou usuário para adaptar o imóvel residencial às suas necessidades, melhorando assim o desempenho do ambiente construído (EBERT; ROMAN, 2006). Silveira, Borenstein e Fogliatto (2001) afirmam que a personalização é uma estratégia dinâmica diretamente relacionada à habilidade de entender as necessidades dos clientes e transformá-las em produtos e serviços de alto valor agregado, sempre do ponto de vista do consumidor. Para esses autores, para que seja adotada, é necessário considerar os processos e os aspectos organizacionais e culturais na sua implementação.

Assim, as empresas precisam gerenciar as informações ao longo de toda a cadeia de suprimentos. Silveira, Borenstein e Fogliatto (2001) completam que são imprescindíveis um eficaz sistema de comunicação e uma gestão de informações no sistema de personalização ao longo de todo o fluxo de valor, desde o fornecedor até o cliente final. Muitas vezes o processo de desenvolvimento de produtos personalizados é negligenciado, por isso é importante que equipes de projeto, produção e fornecedores trabalhem integrados e focados na produção de bens e serviços com esta característica (YASSINE et al., 2004; TILLMANN, 2008).

Pagliaroni e Serra (2012) verificaram a necessidade de um planejamento eficaz que englobe todos os processos de personalização, desde a venda até a entrega do imóvel, de forma a não comprometer o cronograma e causar insatisfação aos clientes. Os processos produtivos dos empreendimentos da construção civil são complexos e possuem altos índices de retrabalhos, muitas vezes devido à carência de planejamento na fase das operações. A inclusão de personalização neste ambiente acaba por agravar ainda mais essa situação (DIAS; SERRA, 2012). Pensando do mesmo modo, Farias (2013) complementa que o nível de retrabalho do empreendimento aumenta com a personalização, pois não há tempo para uma reprogramação do planejamento da produção como um todo.

Frutos (2000) apresenta um sistema de informação para gerenciamento da customização de imóveis residenciais, de forma a obter um fluxo contínuo da decisão vinculando-a aos diversos agentes internos e externos da empresa e otimizando o processo de produção. A modelagem conceitual do problema foi realizada por meio da abordagem orientada a objetos, pela qual foi possível estudar o fluxo de informações gerado a partir da opção de personalização. $O$ estudo de caso foi voltado a uma empresa em particular. Mas verifica-se que podem ser encontrados outros formatos de organização no mercado da construção civil. 
Dessa forma, nota-se a necessidade de analisar o fluxo de informações gerado a partir da decisão e oferta da personalização para clientes em diferentes construtoras, como forma de melhorar o processo de aquisição de materiais e gestão da produção no canteiro de obras. Para isso, foram estudadas quatro empresas atuantes em diferentes regiões do Brasil. Com base na análise desenvolvida, o trabalho também apresenta a proposta de um fluxograma modelo para facilitar a melhoria do processo de personalização de imóveis.

\section{PANORAMA SOBRE A GESTÃO DA PERSONALIZAÇÃO DE IMÓVEIS NO BRASIL}

Frutos (2000), em pesquisa realizada com duas construtoras em Santa Maria (RS), ressalta a opinião dos empresários de que projetos devem ser melhorados no sentido de prever, em sua concepção, as alternativas de modificação, definindo os prazos em função do cronograma das obras. No estudo verificou-se que as principais desvantagens da personalização de imóveis são o desgaste gerado a partir da interação com os clientes; a exigência de um maior controle da informação por parte da organização; a indução de mudanças generalizadas; atrasos no cronograma de obra e dificuldade na aquisição de materiais diversificados e personalizados.

Em pesquisa realizada por Carvalho e Jungles (2004) em Florianópolis (SC), os autores observaram que o procedimento da empresa analisada era o seguinte: a partir da data da compra, o cliente tinha um mês para definir os materiais de acabamento, as louças e metais de sua preferência, bem como mudanças no layout interno do apartamento (utilizando divisórias de gesso acartonado). Foi percebido que o receio de perder consumidores levou a construtora a abrir mão do rigor desse prazo, havendo aqueles que demoraram a definir suas preferências e outros que mudaram suas definições, gerando atrasos e realocações de mão de obra não previstas. Diferenças entre as durações das atividades do planejamento e da execução, e a demora nas definições arquitetônicas pelos compradores foram fatores visualizados que geraram o acúmulo de atividades no final da obra.

Também nessa cidade, Ebert e Roman (2006) verificaram que uma das construtoras estudadas decidiu construir as unidades habitacionais, que ainda não haviam sido comercializadas no início da obra, conforme o projeto padrão. Entretanto, a oferta de flexibilidade total oferecida pela empresa para o empreendimento foi mantida mesmo para estas unidades, gerando posteriormente demolições, desperdício de materiais e atraso na entrega da obra. Ainda nesta pesquisa, a construtora percebeu que a oferta de personalização, por meio de diferentes opções de revestimentos e acabamentos, trouxe como consequência a diminuição da quantidade de um mesmo tipo de material a ser adquirido, o que gerou consequente redução em seu poder de barganha da construtora na negociação com fornecedores de materiais de acabamento.

Machado e Moraes (2008) verificaram em estudo com duas construtoras, atuantes em São Paulo e Porto Alegre, que também houve alteração significativa no processo de aquisição de produtos devido às diferentes especificações e volumes de materiais constantes no empreendimento personalizado. Outro fator relevante percebido foi em respeito ao treinamento do pessoal do almoxarifado e aos procedimentos implementados para controlar todos os materiais. Afinal, quanto maior o número de unidades customizadas, maior o potencial de existência de materiais diversificados, refletindo-se na complexidade de administração dos mesmos. 
Em trabalho realizado por Santana, Oliveira e Meira (2008), sobre a caracterização de sistemas de personalização em construtoras da cidade de João Pessoa (PB), observou-se que não havia planejamento prévio das construtoras com vistas a facilitar a adoção e aplicação do sistema. As empresas adotaram a personalização de maneira informal, ou seja, não havia política interna desenvolvida especificamente para atender as particularidades que são impostas.

Kemmer et al. (2010), em pesquisa realizada na cidade de Fortaleza (CE), verificaram que o processo de personalização pode ser dividido em duas fases: gestão de projetos de personalização ou registro de decisão do cliente, realizada no escritório e a construção de unidades personalizadas, empreendida pela área de produção. Para organizar melhor o processo, estas duas fases precisam ser integradas, por isso, a empresa precisou definir procedimentos internos. Uma das estratégias foi a elaboração de uma carta para o cliente, com o objetivo de informar sobre o processo de produção, maximizar a transparência e evitar atividades que não agregam valor, como falhas durante o processo causados por omissões e erros que interrompem o fluxo contínuo de personalização.

Dias e Serra (2012), em estudo com três construtoras atuantes na cidade de São Carlos (SP), perceberam que apenas duas souberam administrar com maior eficácia a customização, por meio da definição de tipos de alterações possíveis e apresentação de kits de materiais e configurações pré-determinados. As empresas não tinham pretensão de expandir as variedades de personalização oferecidas devido à maior complexidade das atividades, que por diversas vezes geraram atrasos nas obras, e ao custo adicional gerado.

Falconi (2013), em pesquisa realizada em Cuiabá (MT), percebeu que uma das deficiências que podem ser encontradas no processo de personalização de imóveis é a falta de interligação do projeto com o processo de produção na obra. Para essa autora, no desenvolvimento de personalização de projetos e obras da empresa, é importante a disponibilização de uma equipe de atendimento ao cliente para desenvolvimento dos projetos customizados e acompanhamento do serviço de execução da obra para cada apartamento que vier a sofrer alguma alteração.

Farias (2013), em estudo desenvolvido na cidade de Belém (PA), sugere a organização do processo de personalização segundo as metas de reprogramação do processo: respeitar o cronograma da obra na abordagem com o cliente para as solicitações de mudanças na sua respectiva unidade; planejar individualmente os apartamentos customizados; orçar as mudanças nas unidades solicitadas pelos clientes; exigir cumprimento rigoroso do prazo dado ao cliente para entrega do material; estabelecer pagamento antecipado de bancadas e soleiras de granito; criar um espaço específico no almoxarifado para guardar os materiais de clientes; formar equipes de trabalho exclusivas para cada apartamento modificado; destacar um profissional para controlar o andamento dos serviços de acordo com o cronograma geral da obra; fazer check list diário das tarefas executadas nos apartamentos customizados; marcar reuniões quinzenais do engenheiro residente da obra com o arquiteto responsável pelo setor de personalização para atualizar seu status geral e as informações referentes aos apartamentos modificados.

Fernandes (2013) desenvolveu trabalho para investigar os processos de flexibilização e personalização de unidades habitacionais em edificações verticais residenciais de classe média localizadas em Porto Alegre (RS). A pesquisa foi desenvolvida por meio de entrevistas e acompanhamento de obras em quatro empresas construtoras. A partir da análise do estudo de caso foram propostas diretrizes para melhoria da gestão de projetos com possibilidade de modificações, tais como uso de dispositivos móveis com internet sem fio; uso de extranets de projeto e softwares com recurso de 
modelagem em 3D, visando à eficiência da comunicação entre os clientes, projetistas e construtoras, com consequente redução de retrabalho.

Dessa forma, percebe-se que a adoção da personalização de imóveis ocorre de forma abrangente em todo o país, sendo destacados nas pesquisas os aspectos que necessitam ser melhor compreendidos. Assim, é importante continuar estudando o processo de gestão da personalização, propondo soluções para melhorar o fluxo de informações durante os processos de concepção e de construção.

\section{METODOLOGIA}

O método adotado foi o estudo de caso, sendo esta uma pesquisa exploratória, por meio da observação direta e uma série sistemática de entrevistas. Segundo Yin (2001), a investigação de estudo de caso enfrenta uma situação tecnicamente única em que haverá muito mais variáveis de interesse do que pontos de dados, e como resultado, baseia-se em várias fontes de evidências e beneficia-se do desenvolvimento prévio de proposições teóricas para conduzir a coleta e a análise de dados.

Este artigo está baseado em Pagliaroni (2013), que procurou conhecer os processos internos de quatro construtoras envolvidas com personalizações de imóveis, a fim de propor reflexões e soluções para melhoria da gestão. Para a etapa de coleta de dados, foram necessárias três técnicas distintas: pesquisa de autocompletar, entrevista pessoal doméstica e observação in loco. O questionário, utilizado na pesquisa de autocompletar, apresentava 36 questões que abordaram aspectos da personalização, planejamento e suprimentos das empresas. Caracterizouse por ser de fácil entendimento por parte do entrevistado, com questões claras e simples o suficiente para que consiga responder sozinho. A entrevista seguiu o roteiro do próprio questionário, completada por opiniões e sugestões por parte dos entrevistados. A observação in loco consistiu na visita às unidades e aos canteiros de obras de forma a perceber as estratégias de implantação da personalização.

A aplicação do questionário, entrevistas e visitas nas obras foram feitas entre os meses de julho e dezembro de 2012 nas quatro construtoras. Três critérios foram adotados para a seleção das empresas: deveriam contemplar em suas estratégias ações de personalização de seus produtos; apresentar diferentes estágios de customização dos produtos de forma a permitir a análise do fenômeno por diferentes perspectivas operacionais; disponibilidade para fornecer as informações e participar da pesquisa deste trabalho. Os profissionais entrevistados foram os que tinham relação direta com o processo de personalização, conforme descrito no Quadro 2.

\section{BREVE CONCEITO DE PERSONALIZAÇÃO DE IMÓVEIS}

Silveira, Borenstein e Fogliatto (2001) apresentam o conceito de personalização em massa, que tem foco no fornecimento de produtos ou serviços diferenciados por meio de processos flexíveis em grandes volumes e com custos relativamente baixos. É visto como uma ideia sistêmica envolvendo todos os aspectos de venda do produto, desenvolvimento, fabricação e entrega, um círculo completo a partir da opção do cliente até que receba o produto acabado. Os mesmos autores expõem oito níveis de personalização em massa, desde a pura padronização até a pura customização. Neste trabalho foram adotados sete níveis de classificação em função da semelhança no contexto brasileiro dos níveis additional services (serviços adicionais) com additional custom work (trabalhos personalizados adicionais), conforme Quadro 1 a seguir. 
Quadro 1: Níveis de personalização em massa

\begin{tabular}{|l|l|}
\hline \multicolumn{1}{|c|}{ Nível } & \multicolumn{1}{c|}{ Descrição da personalização em massa } \\
\hline Padronização & O padrão puro \\
\hline Uso & $\begin{array}{l}\text { Somente após a entrega, por meio de produtos que podem ser } \\
\text { adaptados para diferentes funções ou situações }\end{array}$ \\
\hline Pacote e distribuição & $\begin{array}{l}\text { Através da distribuição ou acondicionamento de produtos } \\
\text { similares em diferentes formas e tamanhos }\end{array}$ \\
\hline Serviços adicionais & $\begin{array}{l}\text { Adição de serviços sob encomenda em produtos padronizados, } \\
\text { muitas vezes no momento da entrega }\end{array}$ \\
\hline Montagem & $\begin{array}{l}\text { Organização de componentes modulares em diferentes } \\
\text { configurações de acordo com os pedidos dos clientes }\end{array}$ \\
\hline Fabricação & $\begin{array}{l}\text { Fabricação de produtos sob medida para o cliente, seguindo } \\
\text { projetos pré-definidos }\end{array}$ \\
\hline Projeto & $\begin{array}{l}\text { O maior nível de personalização. Projetos colaborativos, } \\
\text { fabricação e entrega dos produtos de acordo com preferências } \\
\text { individuais dos clientes }\end{array}$ \\
\hline
\end{tabular}

Fonte: adaptado de Silveira et al., 2000

Brandão (1997) menciona que as empresas incorporadoras do setor privado brasileiro oferecem a personalização dos produtos por meio de dois tipos de flexibilidade inicial: a flexibilidade planejada e a flexibilidade permitida. A primeira refere-se a uma postura proativa das empresas, que oferecem produtos com vários layouts alternativos (previamente planejados), enquanto a segunda, à oferta de um produto padrão, porém com a possibilidade de alterações pelo consumidor, através de pequenas negociações.

Segundo Pagliaroni (2013), algumas construtoras passaram a oferecer a chamada "personalização livre", que apesar do nome, não é totalmente livre. As empresas oferecem premissas de projeto com as diretrizes necessárias para o cliente elaborar seu projeto personalizado. Cada empresa adota suas normas conforme necessidade e experiência, podendo ter restrições de layout ou tipos de acabamentos.

Observa-se que existem outras classificações no mercado e, em todas, é importante entender como ocorre o processo de personalização de imóveis e as consequências para a gestão do empreendimento como um todo.

\section{ESTUDO DE CASO}

\section{Descrição do processo de personalização nas empresas pesquisadas}

Foram elaboradas diferentes questões que abordam aspectos da personalização, planejamento e gestão dos suprimentos nas empresas. A seguir, no Quadro 2, é apresentado o questionário com as perguntas e respostas de cada construtora estudada.

Quadro 2: Questionário aplicado nas empresas do estudo de caso

\begin{tabular}{|l|l|l|l|l|}
\hline \multicolumn{1}{|c|}{ Perguntas } & \multicolumn{1}{|c|}{ Empresa A } & \multicolumn{1}{|c|}{ Empresa B } & \multicolumn{1}{|c|}{ Empresa C } & \multicolumn{1}{c|}{ Empresa D } \\
\hline Porte da empresa & Grande porte & Grande porte & Grande porte & Médio porte \\
\hline Região de atuação & $\begin{array}{l}\text { Em dezenove } \\
\text { estados } \\
\text { brasileiros }\end{array}$ & $\begin{array}{l}\text { No município de } \\
\text { São Paulo }\end{array}$ & $\begin{array}{l}\text { No nordeste } \\
\text { brasileiro }\end{array}$ & $\begin{array}{l}\text { No interior do estado } \\
\text { de São Paulo }\end{array}$ \\
\hline Padrão das obras & Baixo padrão & Alto padrão & Alto padrão & Alto padrão \\
\hline
\end{tabular}


Quadro 2: Continuação

\begin{tabular}{|c|c|c|c|c|}
\hline Perguntas & Empresa A & Empresa B & Empresa C & Empresa D \\
\hline Área privativa dos imóveis (tamanho médio) & $50 \mathrm{~m} 2$ & $200 \mathrm{~m} 2$ & $200 \mathrm{~m} 2$ & $\begin{array}{l}\text { Residencial: } 140 \mathrm{~m} 2 \\
\text { Comercial: } 90 \mathrm{~m} 2\end{array}$ \\
\hline Cargos dos profissionais entrevistados & $\begin{array}{l}\text { Engenheiro de } \\
\text { Planejamento e } \\
\text { Controle }\end{array}$ & Sócio-diretor & $\begin{array}{l}\text { Coordenador } \\
\text { Lean/Green; } \\
\text { Coordenador } \\
\text { de Projetos; } \\
\text { Coordenador } \\
\text { de Suprimentos; } \\
\text { Gerente de Obras } \\
\end{array}$ & $\begin{array}{l}\text { Engenheiro de } \\
\text { Obras, Gerente de } \\
\text { Orçamentos, Diretor }\end{array}$ \\
\hline Local da obra visitada & São Carlos, SP & São Paulo, SP & Fortaleza, CE & Ribeirão Preto, SP \\
\hline $\begin{array}{l}\text { Quantidade de dormitórios por unidade } \\
\text { habitacional }\end{array}$ & De um a três & Sete & Cinco & Quatro \\
\hline Momento de oferta das personalizações & Início da obra & Início da obra & Início da obra & Início da obra \\
\hline $\begin{array}{l}\text { Existem normas de atendimento para a } \\
\text { personalização? }\end{array}$ & Não & Sim & Sim & Sim \\
\hline $\begin{array}{l}\text { São oferecidos aos clientes diferentes opções } \\
\text { de layout para cada unidade? }\end{array}$ & Sim & Sim & Sim & Sim \\
\hline $\begin{array}{l}\text { É permitido que o cliente apresente um } \\
\text { projeto específico para modificação do } \\
\text { layout da unidade? }\end{array}$ & Não & Sim & Sim & Sim \\
\hline $\begin{array}{l}\text { É permitido que se modifique uma área seca } \\
\text { para área molhada e vice-versa? }\end{array}$ & Não & Sim & Não & Não \\
\hline $\begin{array}{l}\text { São oferecidos aos clientes diferentes opções } \\
\text { para pontos de eletricidade? }\end{array}$ & Sim & Não & Não & Não \\
\hline $\begin{array}{l}\text { É permitido que o cliente apresente um } \\
\text { projeto específico para modificação dos } \\
\text { pontos elétricos da unidade? }\end{array}$ & Não & Sim & Sim & Sim \\
\hline $\begin{array}{l}\text { São oferecidas aos clientes diferentes opções } \\
\text { de acabamento de pisos, revestimentos e } \\
\text { granitos? }\end{array}$ & Sim & Sim & Sim & Sim \\
\hline $\begin{array}{l}\text { É permitido que o cliente escolha os } \\
\text { acabamentos de pisos, revestimentos } \\
\text { e granitos em um fornecedor de sua } \\
\text { preferência? }\end{array}$ & Não & Sim & Sim & Sim \\
\hline $\begin{array}{l}\text { É permitido que o cliente apresente um projeto } \\
\text { específico para modificação dos acabamentos } \\
\text { de pisos, revestimentos e granitos? }\end{array}$ & Não & Sim & Sim & Sim \\
\hline $\begin{array}{l}\text { São oferecidos aos clientes diferentes opções } \\
\text { de pintura? }\end{array}$ & Não & Não & Não & Não \\
\hline $\begin{array}{l}\text { O cliente tem acesso a amostras } \\
\text { dos materiais de personalização } \\
\text { comercializados? }\end{array}$ & Sim & Sim & Sim & Sim \\
\hline $\begin{array}{l}\text { No orçamento da personalização apresentado } \\
\text { ao cliente é apresentado um percentual sobre } \\
\text { os serviços ou um preço fechado? }\end{array}$ & Preço fechado & Percentual & Preço fechado & Preço fechado \\
\hline Existem cronogramas de longo prazo? & Sim & Sim & Sim & Sim \\
\hline $\begin{array}{l}\text { Existem cronogramas de médio prazo } \\
\text { (restrições)? }\end{array}$ & Não & Sim & Sim & Não \\
\hline Existem cronogramas de curto prazo? & Sim & Sim & Sim & Sim \\
\hline $\begin{array}{l}\text { As atividades referentes à personalização } \\
\text { são inseridas em qual nível de planejamento? }\end{array}$ & Curto prazo & Médio prazo & Médio prazo & Curto prazo \\
\hline
\end{tabular}


Quadro 2: Continuação

\begin{tabular}{|c|c|c|c|c|}
\hline Perguntas & Empresa A & Empresa B & Empresa C & Empresa D \\
\hline $\begin{array}{l}\text { A partir de que momento do } \\
\text { empreendimento é levada em consideração } \\
\text { a personalização? }\end{array}$ & Início da obra & $\begin{array}{l}\text { Concepção do } \\
\text { projeto }\end{array}$ & $\begin{array}{l}\text { Concepção do } \\
\text { projeto }\end{array}$ & Início da obra \\
\hline $\begin{array}{l}\text { É estipulado um prazo adicional para entrega } \\
\text { da unidade em caso de personalização? }\end{array}$ & Sim & Sim & Sim & Sim \\
\hline Existem cronogramas de suprimentos? & Não & Não & Sim & Sim \\
\hline $\begin{array}{l}\text { Quem realiza a cotação e a compra dos } \\
\text { materiais do projeto padrão? }\end{array}$ & $\begin{array}{l}\text { Departamento } \\
\text { de suprimentos }\end{array}$ & $\begin{array}{l}\text { Departamento } \\
\text { de suprimentos }\end{array}$ & $\begin{array}{l}\text { Departamento } \\
\text { de suprimentos }\end{array}$ & $\begin{array}{l}\text { Departamento de } \\
\text { suprimentos }\end{array}$ \\
\hline $\begin{array}{l}\text { Quem é o responsável pela compra dos } \\
\text { materiais de personalização? }\end{array}$ & $\begin{array}{l}\text { Própria } \\
\text { empresa }\end{array}$ & Própria empresa & Cliente & Própria empresa \\
\hline $\begin{array}{l}\text { Os materiais comprados são entregues de } \\
\text { uma só vez, ou são feitos cronogramas de } \\
\text { entrega de materiais junto aos fornecedores? }\end{array}$ & Uma só vez & $\begin{array}{l}\text { Cronogramas } \\
\text { junto ao } \\
\text { fornecedor }\end{array}$ & $\begin{array}{l}\text { Cronogramas } \\
\text { junto ao } \\
\text { fornecedor }\end{array}$ & Uma só vez \\
\hline $\begin{array}{l}\text { Os materiais de personalização são } \\
\text { armazenados separadamente por clientes/ } \\
\text { unidades? }\end{array}$ & Não & Sim & Sim & Não \\
\hline $\begin{array}{l}\text { Existe um departamento responsável } \\
\text { exclusivamente pela personalização? }\end{array}$ & Não & Sim & Sim & Não \\
\hline $\begin{array}{l}\text { Existem equipes de trabalhadores } \\
\text { responsáveis exclusivamente pela execução } \\
\text { das personalizações? }\end{array}$ & Não & Sim & Sim & Não \\
\hline $\begin{array}{l}\text { A mão de obra na produção, em sua maioria, } \\
\text { é própria ou subempreitada? }\end{array}$ & Subempreitada & Subempreitada & Subempreitada & Subempreitada \\
\hline $\begin{array}{l}\text { Qual o percentual de unidades } \\
\text { personalizadas nos empreendimentos }\end{array}$ & $40 \%$ & $60 \%$ & $70 \%$ & $30 \%$ \\
\hline $\begin{array}{l}\text { Caso o cliente adquira o apartamento } \\
\text { após o término do prazo de solicitação de } \\
\text { personalização, ainda assim é possível abrir } \\
\text { uma exceção? }\end{array}$ & Não & Não & Sim & Sim \\
\hline $\begin{array}{l}\text { A comercialização das unidades é feita pela } \\
\text { própria empresa, ou por imobiliárias? }\end{array}$ & Imobiliárias & Imobiliárias & $\begin{array}{l}\text { Própria empresa } \\
\text { e imobiliárias }\end{array}$ & $\begin{array}{l}\text { Própria empresa e } \\
\text { imobiliárias }\end{array}$ \\
\hline $\begin{array}{l}\text { Qual o principal motivo para oferecer ao } \\
\text { cliente a opção de personalizar sua unidade? }\end{array}$ & $\begin{array}{l}\text { Facilitar a venda } \\
\text { das unidades; } \\
\text { maior lucro }\end{array}$ & $\begin{array}{l}\text { Imposição do } \\
\text { mercado }\end{array}$ & $\begin{array}{l}\text { Imposição do } \\
\text { mercado }\end{array}$ & $\begin{array}{l}\text { Imposição do } \\
\text { mercado }\end{array}$ \\
\hline
\end{tabular}

Fonte: Pagliaroni, 2013

Verificou-se que os clientes das empresas, ao negociarem a compra de unidades são comunicados da possibilidade de personalizar as unidades, e o contrato a ser firmado entre as partes apresenta as condições em cláusulas correspondentes. Todas as construtoras estudadas comercializam seus empreendimentos via imobiliárias parceiras e, também, as empresas C e D comercializam diretamente com o cliente. Após a venda, entram em contato com os clientes no início das obras para oferecer formalmente as personalizações.

Todas as empresas estudadas afirmam que existe dificuldade de comunicação entre as imobiliárias e si mesmas quanto a este quesito. As construtoras transmitem às imobiliárias todas as informações referentes ao oferecimento da customização aos clientes no momento de venda dos empreendimentos, entretanto, é afirmado que muitas vezes um mal-entendido no momento da venda acaba gerando insatisfação por parte do cliente. Como por exemplo, a imobiliária afirmar para o comprador que ainda é possível personalizar, mas na verdade o prazo para a solicitação já se esgotou.

As empresas estudadas, em sua maioria, afirmam que oferecem a personalização devido à imposição do mercado. Os clientes que desejam personalizar suas unidades, querem que o valor despendido na aquisição 
atenda o máximo possível das suas necessidades. A estratégia da empresa A é aumentar o valor do produto para o cliente, apesar das poucas opções existentes, com isso espera facilitar a venda das unidades e, ao mesmo tempo, ter um retorno considerável por isto. As outras construtoras afirmaram que a personalização é um diferencial que agrega maior valor às suas unidades, mas não veem o lucro como um fator importante. A empresa $\mathrm{C}$ comentou que, em alguns momentos, teve prejuízo com estes serviços, pois não lhe trouxeram benefícios financeiros.

Os imóveis oferecidos nos empreendimentos das empresas variaram de um a sete dormitórios, dependendo do padrão do empreendimento. Quanto maior o padrão da obra, maior a área da unidade e, consequentemente, maior a quantidade de dormitórios. Um aspecto a ser analisado na quantidade de dormitórios das unidades é que pode ser variável, dependendo da escolha do layout por parte do cliente, que pode transformar um quarto em sala, por exemplo.

As modalidades de personalização utilizadas pelas empresas estudadas são variadas. A empresa A utiliza a estratégia de oferecimento de kits pré-definidos, com possíveis alterações em layout, pisos, revestimentos, bancadas, soleiras e pontos de elétrica. O cliente escolhe os kits de sua preferência e a empresa apresenta o orçamento de cada para aceite do comprador. Os orçamentos dos kits são realizados em momento anterior ao início da obra.

As empresas B, C e D oferecem diferentes opções de layout e acabamentos aos clientes, mas a principal customização oferecida é a personalização "livre”, na qual o cliente pode elaborar os projetos de sua unidade conforme queira, dentro de normas de atendimento ou premissas da empresa para a personalização. Esta modalidade aumenta consideravelmente o valor do produto ao cliente, entretanto é necessário um alto grau de gestão nos empreendimentos. As empresas estudadas que oferecem este tipo de personalização apresentam várias dificuldades, como a demora no retorno do cliente com os projetos, a falta de compatibilidade dos projetos entregues pelo cliente e até insatisfações por parte do comprador devido a impasses entre as partes.

Alguns destes problemas foram resolvidos pela empresa B: quando ocorre a demora para o retorno dos clientes, o projetista é penalizado com a rescisão do contrato e a compatibilidade dos projetos de personalização é realizada pela construtora. A empresa B se considera rígida quanto aos procedimentos, mas afirma que abrir exceções para os clientes facilita o trabalho de personalizar e não gera insatisfações entre as partes. Já as empresas C e D admitem que abrem exceções quanto ao prazo para aceitar projetos de personalização, devido ao receio de deixar o cliente insatisfeito, apesar de isso resultar em custos com retrabalhos nas obras.

Todas as empresas estudadas possuem mostruários de todos os materiais de acabamento de personalização oferecidos. Assim, os clientes podem escolher melhor o acabamento desejado. A empresa B apresenta separadamente os custos de material, mão de obra e a taxa de administração cobrada para realizar as customizações. Diferente das outras três companhias estudadas que embutem no orçamento o valor da administração não deixando explícito para o cliente o quanto está desembolsando realmente com cada item da personalização.

Todas as empresas possuem um setor de suprimentos que possui importância estratégica por conduzir o processo de aquisição dos materiais.

Dentre as empresas estudadas, as B, C e D realizam uma análise do histórico das personalizações contratadas para incluí-las como possível projeto padrão em empreendimentos futuros. As construtoras A e C analisam a rentabilidade das customizações visando alterar os tipos de mudanças a serem oferecidas nos próximos empreendimentos.

Todas as empresas estudadas elaboram diferentes níveis de planejamento. As A e D realizam planejamento de médio prazo utilizandose do cronograma de longo prazo, já as construtoras B e C realizam 
um planejamento de médio prazo com cronogramas de restrições. Os cronogramas de longo prazo adotados abrangem todo o empreendimento, enquanto os cronogramas de curto prazo são elaborados pelo departamento de obras e se resumem a uma programação semanal.

Os cronogramas de médio prazo adotados pelas empresas B e C têm horizonte de seis a oito semanas e incluem atividades de restrições, ou seja, trabalhos que necessitam ser realizados para liberar a execução da próxima atividade. A diferença entre as empresas B e C é que a primeira contrata uma empresa especializada para realizar e acompanhar os planejamentos dos empreendimentos e a segunda realiza os planejamentos em um departamento interno da própria empresa. Esta prática adotada pela empresa B é considerada pelo sócio-diretor como uma estratégia para ganhar superioridade por combinar as forças internas da empresa com as melhores práticas em planejamento existentes no mercado.

A empresa $C$ agrega ao seu planejamento de curto prazo as atividades de fluxo chamadas de "proteção da produção", ou seja, atividades de abastecimento de materiais, ferramentas, equipamentos, entre outros, para a realização das atividades de processamento (execução, propriamente dita) sem interferências por falta de materiais, ferramentas, equipamentos etc. Paralelamente às atividades de fluxo, a empresa $C$ apresentou a utilização da ferramenta Kanban com o uso de cartões para solicitar a produção e entrega de argamassa. Além disso, as empresas C e B realizam cronogramas de entregas junto aos fornecedores dos materiais conforme necessidade, e destinam os materiais de personalização diretamente para as unidades em que serão aplicados.

A partir deste estudo será proposto a seguir o detalhamento do fluxograma observado do processo de personalização em cada empresa.

\section{FLUXOGRAMAS DOS PROCESSOS DE PERSONALIZAÇÃO}

Juntamente com os questionários aplicados nas empresas, foram realizadas entrevistas com o objetivo de elaborar os fluxogramas dos processos de personalização. Os fluxogramas ilustram os processos internos das empresas, desde a venda do imóvel para o cliente até a entrega de materiais na obra e execução, mostrando a comunicação entre os departamentos envolvidos.

A seguir, na Figura 1, é apresentado o fluxograma dos processos de personalização da empresa A, conforme relatos e entrevista realizada.

Na empresa A, o processo de oferecimento de opções de personalização só é executado caso não se tenha iniciado a alvenaria do edifício. Por oferecer somente kits, possui processos internos simples para a aquisição de materiais. No orçamento da obra consta a quantidade total de material padrão a ser utilizada; caso exista alguma personalização, o departamento de obras soma a quantidade personalizada no pedido com o fornecedor e subtrai a quantidade padrão que não será mais utilizada. Como os fornecedores de materiais padrão e de customização da empresa A são os mesmos e possuem contratos de fornecimento de material, não existem maiores dificuldades no processo de aquisição de materiais da empresa.

Outro aspecto importante na aquisição de materiais da empresa A é que, previamente ao início da obra, são realizados contratos de fornecimento de materiais junto aos fornecedores dos principais insumos, como cimento, agregados, concretos, pisos, revestimentos, pedras e tintas. Adicionalmente aos contratos, é autorizado ao departamento de obras realizar as compras de certos materiais contratados, como cimento, agregados e concreto, diretamente com os fornecedores. Previamente, é acordado um preço unitário pelo material, junto ao fornecedor, e ao final de um período, as quantidades adquiridas são pagas pela empresa. Estas medidas aliviam o volume de cotações e compras a ser realizadas pelo departamento de suprimentos durante a obra. 


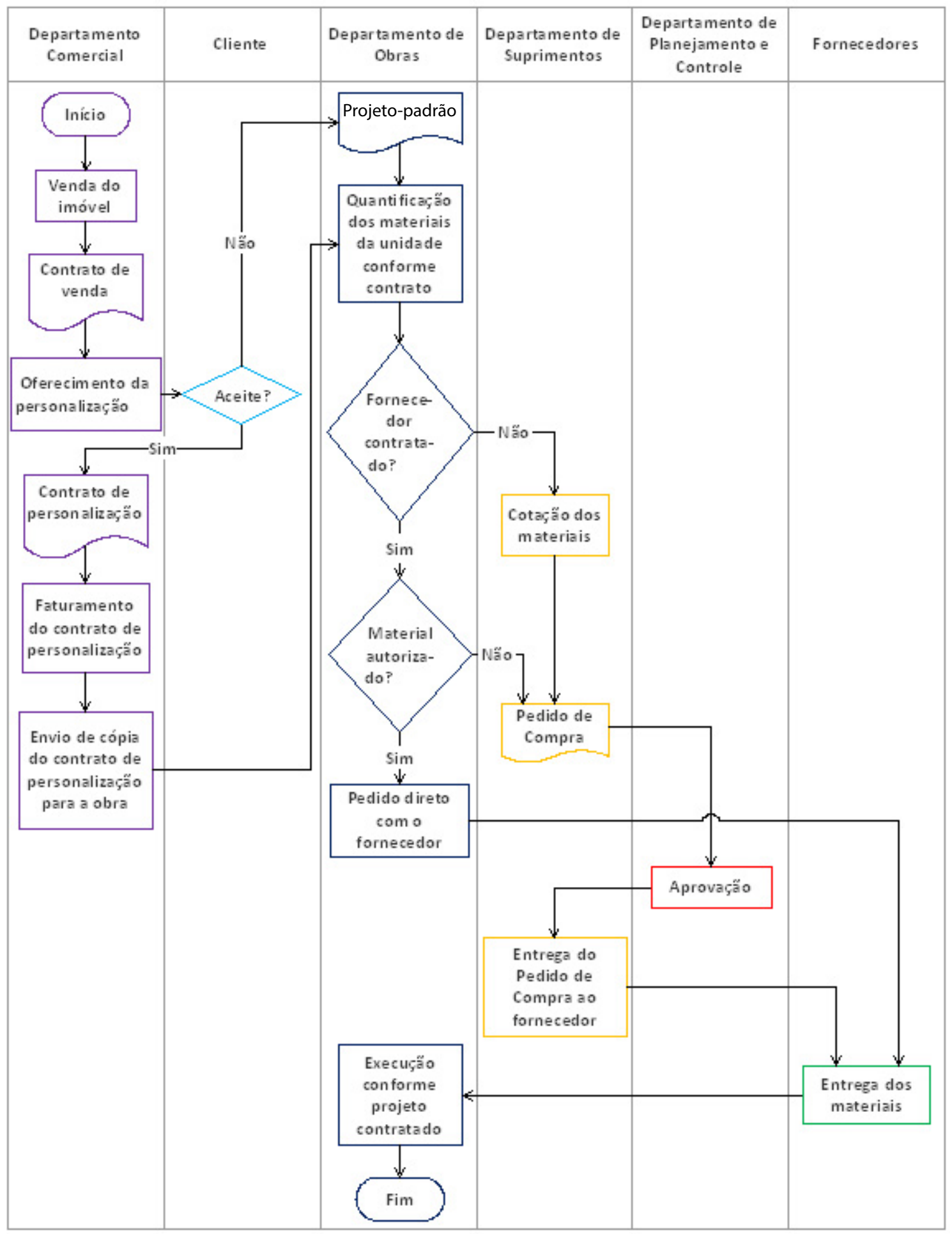

A empresa B, por oferecer personalização "livre”, possui uma estrutura de processos internos mais elaborada quando comparada a da empresa anterior, conforme mostrado na Figura 2.
Figura 1: Fluxograma dos processos de personalização da empresa A

Fonte: Pagliaroni, 2013 


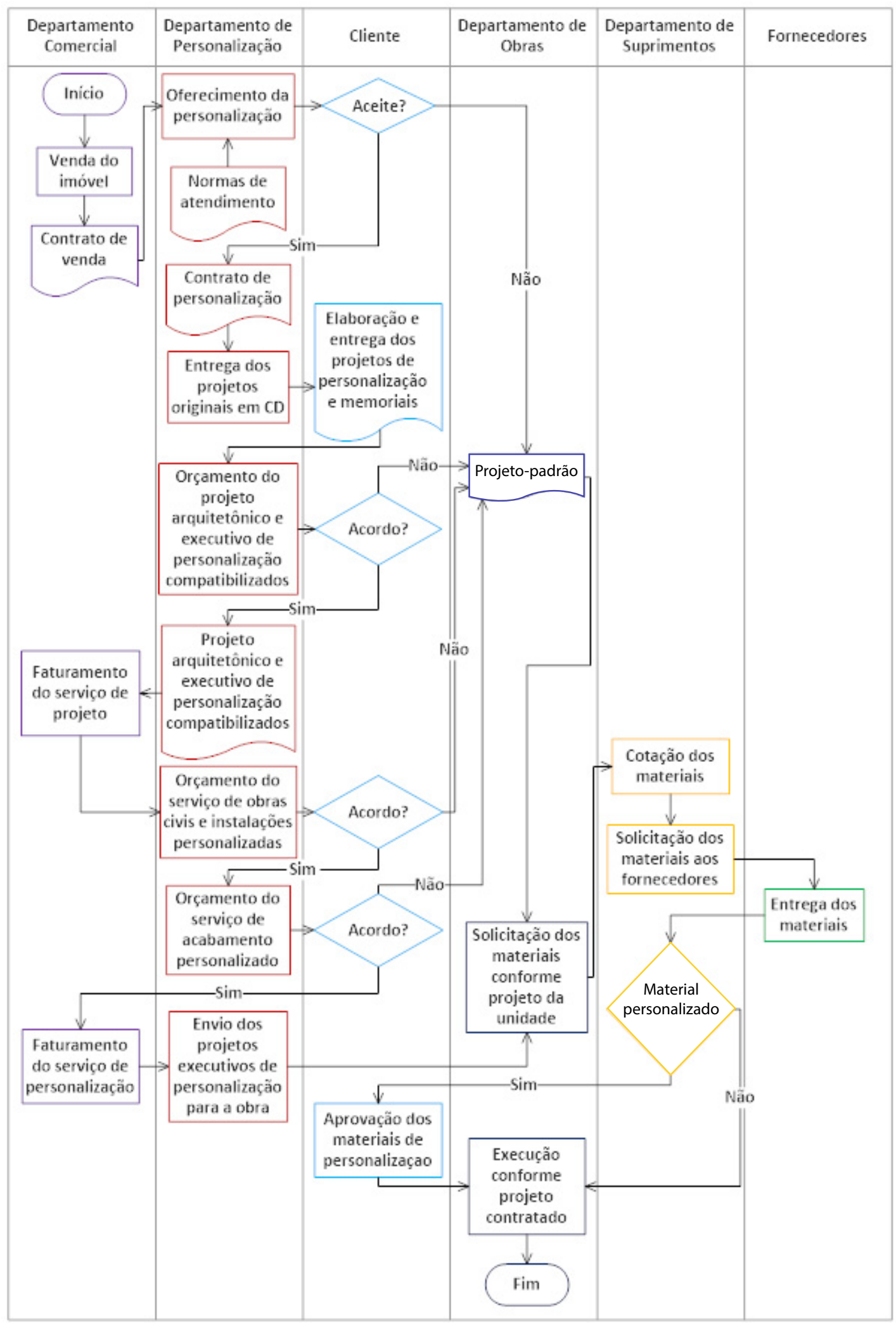

Figura 2: Fluxograma dos

processos de personalização da empresa B

Fonte: Pagliaroni, 2013 
A empresa B realiza várias reuniões com clientes quando é contratada a personalização. São realizadas três etapas importantes para sua realização: processos de projeto, que consistem na entrega do projeto de customização pelo cliente, orçamento e aprovação do serviço de projeto; processos de obras civis e instalações personalizadas, que consistem na elaboração do orçamento e aprovação; e processos de serviços de acabamento, que consistem na elaboração do orçamento e aprovação por parte do comprador. Os projetos executivos somente são enviados para a obra após o cliente aprovar todos os orçamentos referentes à personalização. Caso em alguma das etapas o consumidor não aprove os orçamentos, ou não retorne as informações necessárias dentro do prazo estipulado, a alteração é cancelada.

O cliente pode escolher o material de acabamento de sua preferência em qualquer fornecedor que atenda a obra. Devido a este fato, um aspecto observado na empresa B é que é necessário o cliente aprovar os materiais de acabamento de sua unidade após entrega na obra. A empresa não executa o serviço enquanto o material não for aprovado.

A empresa $C$, apesar de oferecer uma personalização próxima à oferecida pela B, possui um modelo de processos internos diferente, conforme Figura 3.

A empresa C oferece personalização "livre", sendo que o cliente pode escolher entre os materiais fornecidos pela própria companhia, com poucos tipos diferentes, ou pode adquirir o material por conta própria e se responsabilizar pela entrega na obra. $\mathrm{O}$ consumidor tem a liberdade de escolher o acabamento de sua preferência no fornecedor que preferir, mas este modo de oferecer a personalização acaba criando dificuldades para o comprador e para a própria empresa.

A empresa $C$ apresenta muitos problemas para receber os materiais dos clientes e gerenciar, após o recebimento, sua destinação correta. Pode ocorrer de o cliente adquirir material com o fornecedor e ser entregue na obra após o prazo estipulado. Desta maneira, ou a obra atrasa pela demora dos materiais, ou a empresa cancela a personalização na unidade e o cliente deverá se responsabilizar junto ao fornecedor, criando uma grande insatisfação por parte do consumidor. Ou seja, a empresa $C$ oferece a personalização, mas coloca na responsabilidade do cliente a aquisição e administração da aquisição dos materiais para tal.

O trabalho do departamento de suprimentos da empresa $C$ neste processo é simplesmente atualizar as quantidades de materiais pré-estabelecidas em projeto, quando são contratadas as personalizações, e solicitar os materiais padronizados para os fornecedores.

A empresa D trabalha com um modelo de processos internos mais simples, apesar de oferecer personalização "livre", conforme mostrado na Figura 4. 


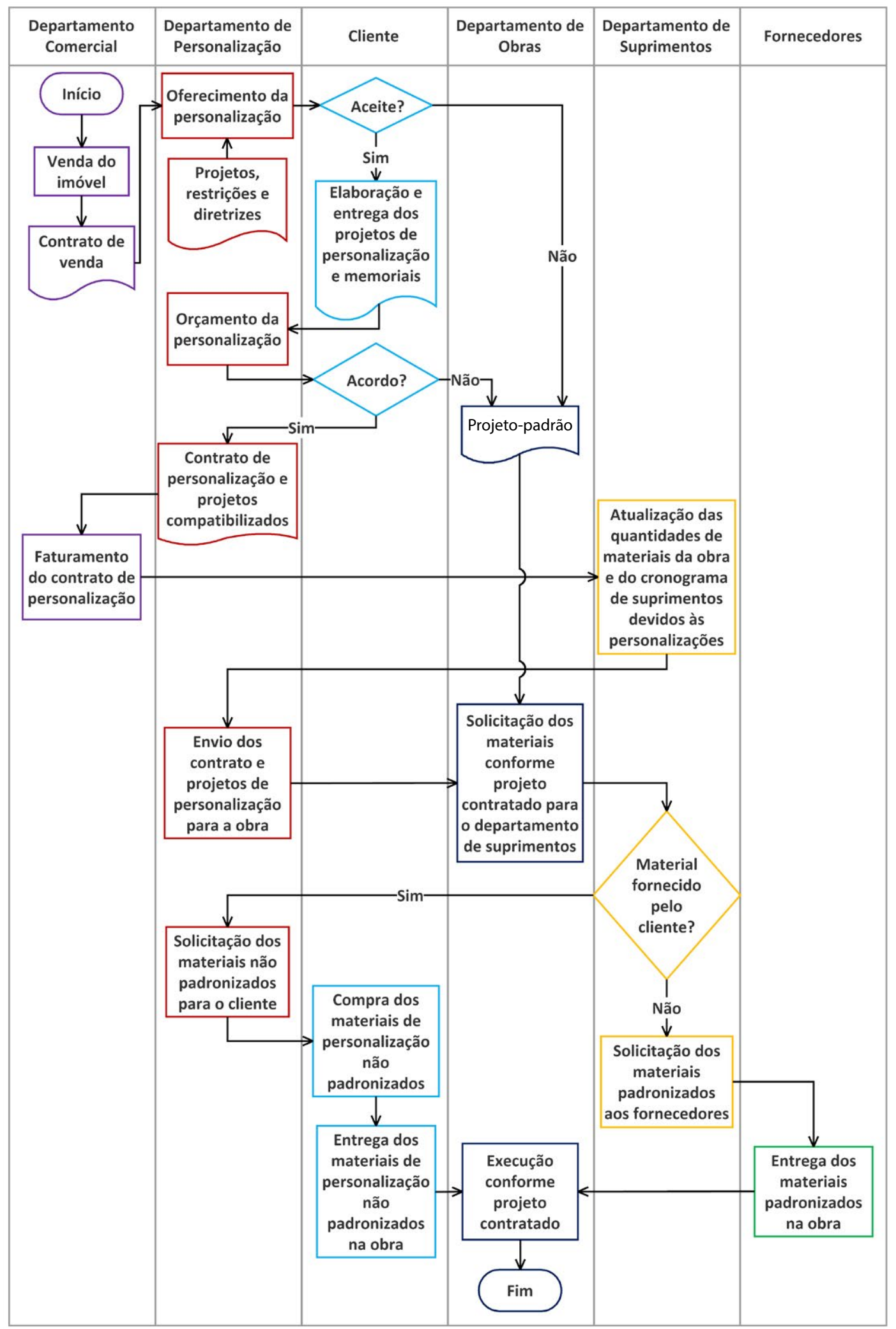

Figura 3: Fluxograma dos

processos de personalização da empresa C

Fonte: Pagliaroni, 2013 


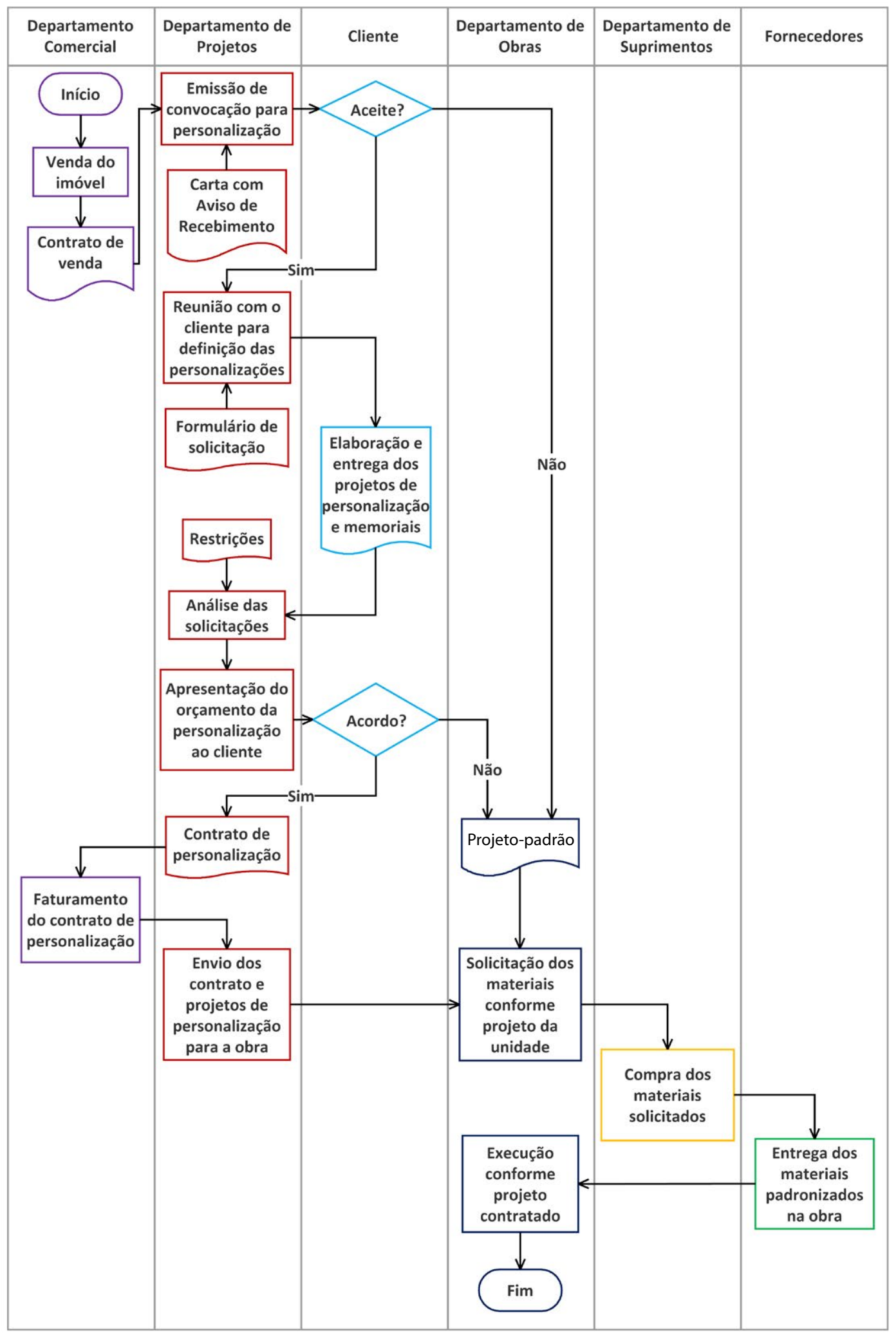

Figura 4: Fluxograma dos processos de personalização da Empresa D

Fonte: Pagliaroni, 2013 
A empresa D possui um departamento de projetos que realiza somente uma reunião com os clientes para orientar as customizações a ser realizadas nas unidades. Os compradores ficam responsáveis por contratar os projetistas da personalização das unidades de acordo com as premissas e diretrizes apresentadas pela empresa.

Um problema verificado na empresa $\mathrm{D}$ é que os projetos elaborados pelos profissionais contratados pelos clientes são em padrões diferentes dos projetos executivos da própria empresa, podendo levar a problemas de comunicação, falta de informação e mau entendimento na obra no momento da execução. Por exemplo, o departamento de obras critica que alguns projetos são entregues sem cotas de referência.

A partir do levantamento em cada empresa, será elaborada a seguir uma análise mais comparativa das situações observadas.

\section{ANÁLISE GERAL}

Em todas as empresas, para realizar uma customização, é necessário executar diferentes processos internos. Quanto maior as possibilidades de personalização, maior é a necessidade de comunicação entre os departamentos envolvidos. Esta afirmação fica clara quando se compara os fluxogramas das construtoras estudadas. A empresa A, por oferecer simples kits de personalização, possui poucos processos, enquanto as empresas B, C e $D$, que executam formas variadas de personalizações necessitam de mais processos para atender as solicitações dos clientes.

Um dos problemas apresentados nas empresas estudadas foi a falta de compatibilização dos projetos de personalização. A construtora B foi a que afirmou não ter este tipo de problema, pois possui um departamento que compatibiliza todos os projetos personalizados entregues pelo cliente, entretanto este serviço é cobrado, fazendo parte do orçamento.

Outro problema apresentado é o atraso dos clientes com o retorno das informações necessárias para a continuação dos processos da personalização. Contribuem para este atraso aceites para customizar, realização dos projetos e aprovações de orçamentos. Além disto, a empresa $C$ deixa na responsabilidade dos clientes a compra dos materiais personalizados, podendo ocorrer a entrega dos mesmos após o prazo estabelecido.

Devido aos diferentes pedidos de materiais, é necessário gerenciar seu recebimento para estocá-los em locais que fiquem separados por unidades ou até, se possível, no próprio apartamento em que será aplicado. A empresa B solicita aos fornecedores que elaborem as notas fiscais dos materiais endereçadas diretamente à unidade de aplicação do material.

Verificou-se que existe falha no alinhamento do fluxo de informações entre obra, departamento de suprimentos e fornecedor, sendo que as obras costumam solicitar materiais antes do necessário e também em quantidades maiores, minimizando os eventuais problemas de falta de materiais e o atraso na entrega. Entretanto, pode acontecer dos materiais serem entregues em quantidades e prazos incompatíveis com o andamento da obra. Foi relatado que muitas vezes as obras não estão preparadas para receber os materiais, além de todos os problemas inerentes da falha na aquisição de suprimentos, como grandes e inadequados estoques, falta de locais para armazenamento e perda de material devido ao transporte e aos retrabalhos.

Estas e outras dificuldades oriundas da personalização de imóveis fizeram com que a empresa C abandonasse a personalização "livre", passando a oferecer somente a personalização em massa (mais padronizada) ou entregando o apartamento sem acabamento algum.

O Quadro 3, seguinte, apresentar uma síntese sobre os níveis de personalização oferecidos pelas empresas estudadas a partir da classificação de Silveira et al. (2000.). 
Quadro 3: Níveis de personalização em massa observados

\begin{tabular}{|l|c|c|c|c|}
\hline Níveis de personalização em massa & A & B & C & D \\
\hline Padronização & $X$ & $X$ & $X$ & $X$ \\
\hline Uso & $X$ & $X$ & $X$ & $X$ \\
\hline Pacote e distribuição & $X$ & $X$ & $X$ & $X$ \\
\hline Serviços adicionais & $X$ & $X$ & $X$ & $X$ \\
\hline Montagem & & $X$ & $X$ & $X$ \\
\hline Fabricação & & $X$ & $X$ & $X$ \\
\hline Projeto & & $X$ & $X$ & $X$ \\
\hline
\end{tabular}

Fonte: Pagliaroni, 2013

Observa-se que independente do padrão e da quantidade de unidades, todas as empresas apresentaram o oferecimento de níveis diferenciados de personalização em massa.

Nesta amostra de empresas do estudo de caso foi possível verificar que somente duas das quatro possuem um departamento específico para personalização. Estas duas empresas são as que apresentaram os maiores índices de customização, 60\% e 70\% das unidades dos empreendimentos. Enquanto as outras apresentam índices de $30 \%$ e $40 \%$. Isso mostra que, quanto maior a demanda por personalização, maior a necessidade de departamentos e profissionais específicos para sua realização.

Será proposto a seguir o fluxograma modelo para auxiliar no processo de personalização, conforme objetivo inicial.

\section{PROPOSTA PARA GESTÃO DA PERSONALIZAÇÃO DE IMÓVEIS}

Um aspecto importante observado nos processos de personalização das empresas estudadas foi a existência do departamento de personalização ou um setor que seja responsável pelos processos inerentes a essa prática. Este departamento deve ser responsável pela interação do cliente com a empresa e, com isso, analisar as solicitações de personalização, atendendo ao máximo as exigências dos compradores.

Considerando a experiência e as informações coletadas, apresentase na Figura 5 uma proposta para um fluxograma modelo dos processos de personalização. Verificou-se também a necessidade da retirada da possibilidade de compras de materiais pelos clientes, por entender que esta etapa pode se tornar um gargalo no processo e não contribui para aumentar o valor do produto. É importante definir também cargos, responsabilidades, procedimentos e ferramentas gerenciais que melhorem a gestão do processo de personalização. 


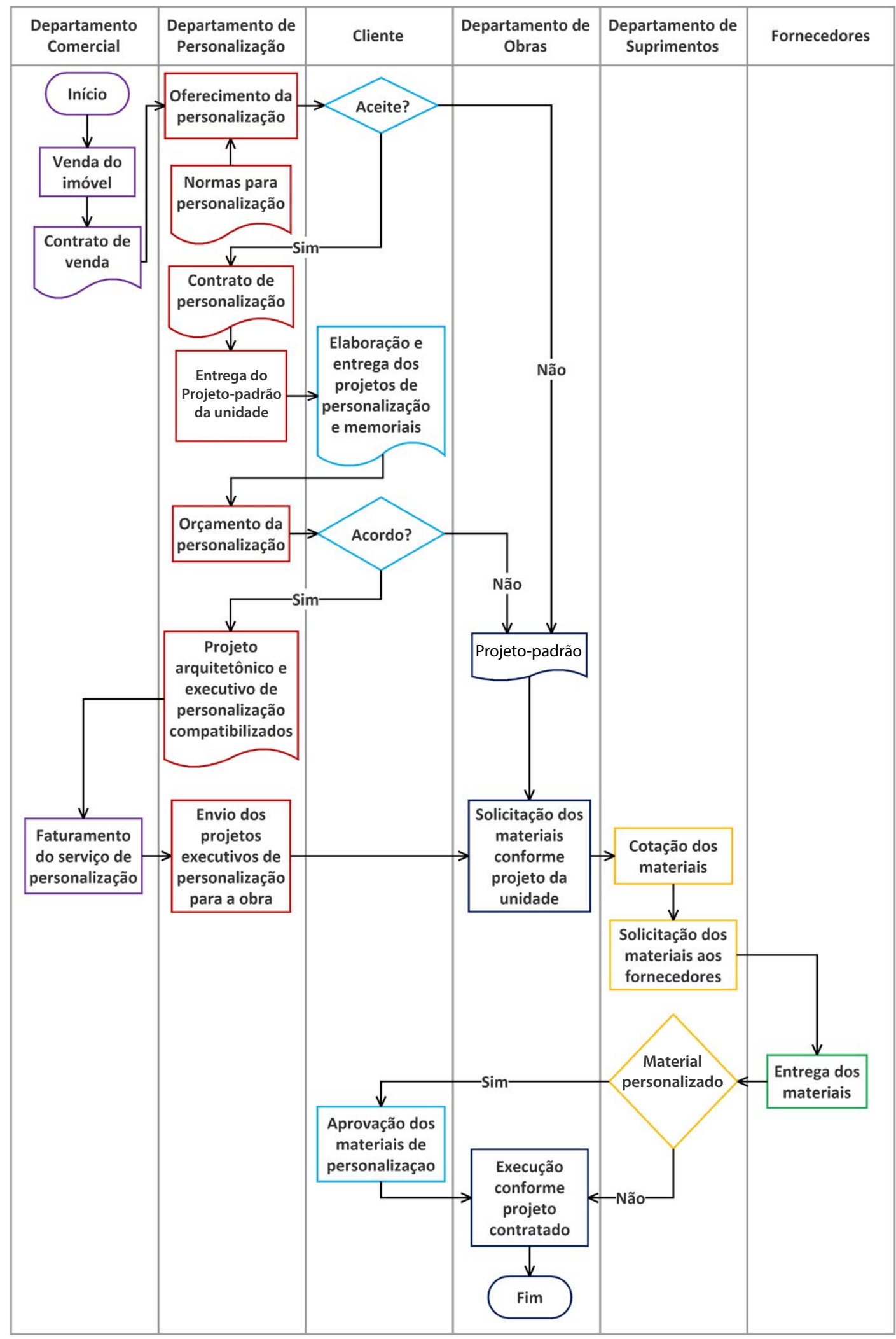

Figura 5: Fluxograma

modelo para os processos de personalização

Fonte: Pagliaroni, 2013 
Na tentativa de propor este fluxograma modelo, foram percebidas que as particularidades de cada empresa, como cultura, estrutura organizacional, exigência de mercado, padrão das obras e classe social do público alvo, podem interferir no mesmo. Desta forma, é importante que cada construtora defina seus processos internos para atingir as estratégias principais da personalização: aumentar o valor de seus produtos e atender as necessidades dos clientes.

\section{CONCLUSÕES}

Os resultados da pesquisa mostram que a personalização de imóveis é uma ferramenta para as empresas aumentarem o valor de seus produtos, atendendo as diferentes necessidades dos clientes. A personalização vem aumentando devido ao crescimento do mercado competitivo da construção civil, a melhoria da renda da população e ao aumento da exigência dos consumidores.

Um aspecto verificado nas empresas estudadas é que quanto maior a área das unidades e maior o padrão de acabamento dos empreendimentos, maior é a liberdade para a realização das personalizações. Conforme o nível de personalização oferecido nos empreendimentos, devem ser realizados estudos desde a fase de concepção do empreendimento, pois existem personalizações que dependem de fatores estruturais, como existência de pilares, vigas e paredes estruturais.

O oferecimento da personalização aos clientes acarreta na necessidade de uma gestão de alta qualidade por parte das empresas. As unidades padrão comercializadas pelas empresas possuem características de repetitividade que facilitam a gestão e o aprendizado pelos operários. Já a personalização apresenta condições individualizadas que geram necessidade de projetos específicos e maior atenção por parte dos executores.

A quantidade de projetos, materiais e mão de obra que devem ser gerenciados aumenta consideravelmente com a personalização. Os materiais devem ser conferidos com o memorial descritivo de cada projeto de personalização e separados individualmente por unidades, as unidades em execução devem ser verificadas de acordo com os projetos de personalização, e anteriormente à entrega da unidade ao cliente deve ser realizada uma inspeção para verificar se todas as solicitações em projeto foram atendidas.

Para gerenciar toda esta variedade de insumos, é importante realizar um planejamento de alto nível, principalmente com a elaboração de planejamentos de médio prazo com cronogramas para aquisição de suprimentos, nas quais os departamentos de planejamento, suprimento e obra trabalhariam juntos para identificar as restrições e tarefas das próximas semanas, incluindo as particularidades dos prazos de entrega dos materiais de personalização.

As vendas de imóveis das empresas estudadas são realizadas por imobiliárias contratadas ou pelas próprias companhias. Em ambos os casos, as empresas constroem apartamentos modelo para que os clientes possam verificar visualmente o produto que estão adquirindo. De mesmo modo, é necessário deixar transparente ao cliente quais materiais fazem parte do contrato de personalização oferecido pela empresa. Todas as empresas estudadas tinham, à disposição do cliente, mostruários dos materiais de acabamento de personalização.

Em todas as empresas estudadas, os processos de personalização passam por diferentes departamentos internos, além de imobiliárias, fornecedores, arquitetos e clientes. Estes relacionamentos e trocas de informações devem ter maior maturidade para atingir os objetivos principais da personalização. As empresas estudadas apresentaram problemas de comunicação entre as partes envolvidas nos processos de customização. Para uma melhoria na 
gestão, é de grande importância a criação de um departamento exclusivo de personalização que fique responsável por centralizar, organizar e transmitir as informações necessárias para cada parte envolvida nos processos de personalização.

Observou-se que, apesar de a personalização ser justamente a diferenciação do padrão, um atrativo para os clientes, é necessário criar limites, para que esta estratégia não dificulte a gestão da obra e o desenvolvimento do empreendimento.

\section{REFERÊNCIAS}

BRANDÃO, D. Q. Flexibilidade, variabilidade e participação do cliente em projetos residenciais multifamiliares: conceitos e formas de aplicação em incorporações. 1997. 235p. Dissertação (Mestrado em Engenharia Civil) Universidade Federal de Santa Catarina, Florianópolis, 1997.

BRANDÃO, D. Q.; HEINECK, L. F. M. Participação do cliente através da flexibilização dos projetos de edificações: um projeto de pesquisa em desenvolvimento. In: ENCONTRO NACIONAL DE ENGENHARIA DE PRODUÇÃO, 16., 1996, Piracicaba. Anais... Piracicaba: Abepro, 1996. 10p.

CAMPANHOLO, J. L. Construção personalizada: uma realidade do mercado. Téchne, São Paulo, n. 41, p. 63-66, jul./ago. 1999.

CARVALHO, L. O.; JUNGLES, A. E. Análise da programação e da execução de um edifício de apartamentos personalizados. In: CONFERENNCIA LATINO-AMERICANA DE CONSTRUÇÃO SUSTENTÁVEL, 1., ENCONTRO NACIONAL DE TECNOLOGIA DO AMBIENTE CONSTRUÍDO, 10., 2004, São Paulo. Anais... Porto Alegre: Antac, 2004. 10p.

DIAS, C. M.; SERRA, S. M. B. Customização de imóveis verticais para habitações de interesse social. In: ENCONTRO NACIONAL DE TECNOLOGIA DO AMBIENTE CONSTRUÍDO, 14., 2012, Juiz de Fora. Anais... Porto Alegre: Antac, 2012.14p.

EBERT, M. R.; ROMAN, H. R. A melhora do desempenhodoambienteconstruídoatravés da flexibilidade inicial de apartamentos. In: WORKSHOP DESEMPENHO DE SISTEMAS CONSTRUTIVOS, 1., 2006, Chapecó. Anais... Chapecó: Unochapecó, 2006. 8p.

FALCONI, T. M. A. Personalização de projetos e obras em construtora de edificações residenciais: estudo de caso. 2013. 150f. Dissertação (Mestrado em Engenharia de Edificações e Ambiental) - Universidade Federal de Mato Grosso, Cuiabá, 2013.

FARIAS, R. W. F. O processo de personalização de apartamentos: estudo de caso em um edifício multifamiliar na cidade de Belém. Revista Especialize, Goiânia, 5. ed., n. 5, v. 1, jul. 2013.

FERNANDES, R. S. Flexibilização e personalização de unidades habitacionais: estudo de caso em Porto Alegre. 2013. 154f. Dissertação (Mestrado em Engenharia Civil) - Universidade do Vale do Rio dos Sinos, São Leopoldo, 2013

FRUTOS, J. D. Desenvolvimento de um sistema de informação para a interação ágil entre clientes e empresas construtorasincorporadoras de prédios residenciais. 2000. 112f. Dissertação (Mestrado em Administração) - Universidade Federal do Rio Grande do Sul, Porto Alegre, 2000.

KEMMER, S. L. et al. Application of lean principles to manage a customization process. In: ANNUAL CONFERENCE OF THE INTERNATIONAL GROUP FOR LEAN CONSTRUCTION, 18., 2010, Haifa. Proceedings... Routledge: IGLC, 2010. p. 306-315.

MACHADO, A. G. C.; MORAES, W. F. A. Customização em massa na construção civil. Revista Brasileira de Gestão e Negócios, São Paulo, v. 10, n. 29, p. 347-364, 2008.

PAGLIARONI, M. A. P. Análise da gestão do processo de personalização de imóveis considerando os princípios da construção enxuta e o setor de suprimentos. 2013. 231f. Dissertação (Mestrado em Estruturas e Construção Civil) - Universidade Federal de São Carlos, São Carlos, 2013.

PAGLIARONI, M. A. P.; SERRA, S. M. B. Análise da integração do planejamento tático e - setor de suprimentos considerando a personalização de imóveis. In: ENCONTRO NACIONAL DE TECNOLOGIA DO AMBIENTE CONSTRUÍDO, 14., 2012, Juiz de Fora. Anais... Juiz de Fora: UFJF, 2012. p. 1422-1431.

SANTANA, C. L.; OLIVEIRA, D. N. S.; MEIRA, A. R. Caracterização de sistemas de personalização em construtoras da cidade de João Pessoa. In: ENCONTRO NACIONAL DE TECNOLOGIA DO AMBIENTE CONSTRUÍDO, 12., 2008, Fortaleza. Anais... Fortaleza: UFC, 2008. 9p. 
SILVEIRA, G.; BORENSTEIN, D.; FOGLIATTO,

F. S. Mass customization: literature review and research directions. International Journal of Production Economics, Amsterdam, v. 72, n. 1, p. 1-13, 2001.

TILLMANN, P. A. Diretrizes para a adoção da customização em massa na construção habitacional para baixa renda. 2008. 168f.

Dissertação (Mestrado em Engenharia Civil)
- Universidade Federal do Rio Grande do Sul, Porto Alegre, 2008.

YASSINE, A. et al. Investigating the role of IT in customized product design. Production Planning and Control, Abingdon, v. 15, n. 4, p. 422-434, 2004

YIN, R. K. Estudo de caso: planejamento e métodos. 2. ed. Porto Alegre: Bookman, 2001. 
